ORIGINAL ARTICLE

\title{
Physician performance information and consumer choice: a survey of subjects with the freedom to choose between doctors
}

\author{
S-H Cheng, H-Y Song
}

Qual Saf Health Care 2004;13:98-101. doi: 10.1136/qshc.2003.006981

See end of article for authors' affiliations ......................

Correspondence to: Dr S-H Cheng, Associate Professor, Institute of Health Policy and Management, College of Public Health, National Taiwan University, Jen-Ai Road, Taipei, Taiwan 100; shcheng@ha.mc.ntu. edu.tw

Accepted for publication 25 August 2003
Background: Increasing efforts have been made to provide information to help consumers to select a healthcare provider, but the public release of hospital performance data has had only a limited impact on consumer choice.

Objectives: To understand the experience of consumers in searching for physician performance information and to investigate the potential impact on their propensity to change doctors if hypothetically provided with physician specific performance information.

Design: A nationwide telephone interview survey using a structured questionnaire.

Setting: The survey was conducted in Taiwan, a country with a universal health insurance programme where residents are free to choose between physicians for any medical consultation.

Participants: 4015 adults aged over 20 years contacted by random digit dialling telephone calls.

Main outcome measures: Subjects were asked (1) if they have ever compared the quality of care provided by physicians in their area; (2) if they would consult a performance report if it was available; and (3) if they would change doctors on the basis of information provided in the report.

Results: Approximately half the subjects had made comparisons between doctors; $73 \%$ stated that they would consult a performance report if it was available, and $77 \%$ were prepared to change doctors if their doctor performed badly in the report.

Conclusions: Providing physician specific performance reports to the public may be viewed favourably by consumers of health care and have a significant impact on physician selection and hence quality improvement.
! nformation to aid consumers in the selection of a preferred healthcare provider is lacking in many countries. While efforts to release hospital performance data to the public have been made in the last decade in the US and UK, ${ }^{1}$ recent reviews and studies suggest that the public release of hospital performance data has had only a limited impact on the selection of physicians, hospitals, and healthcare plans by consumers. $^{2-6}$ Results from field surveys of insurance beneficiaries also show that only a small proportion of the respondents used the released information to aid in decision making. ${ }^{7-9}$ There are two possible explanations for this-a lack of familiarity of consumers with comparative healthcare quality information ${ }^{71}$ and a limited number of providers from which they can choose. ${ }^{211}$ The limited impact of the dissemination of such information on consumer decision making is not therefore surprising.

Given the constraints on the freedom of consumers to choose between healthcare plans or providers, it is difficult to predict the potential effect of the provision of performance related information. Although recent studies have shown that providing quality reports may influence consumers' selection of health plans, ${ }^{12}{ }^{13}$ previous reports revealed that access to preferred physicians is an important factor in choosing health plans. ${ }^{74}$ We have therefore used hypothetical scenarios to investigate the potential impact of providing physician specific performance information to consumers who, under a universal health insurance plan in Taiwan, enjoy a high degree of freedom to choose among doctors.

In Taiwan in 2000 approximately $96 \%$ of the 22.3 million citizens were enrolled in the compulsory National Health Insurance (NHI) programme and about 16300 (94\%) clinics and hospitals had NHI contracts to provide healthcare services to the beneficiaries (box 1). Because of the absence of a referral system in Taiwan, people are free to choose any NHI contracted physician in clinics or hospitals. Moreover, the average number of annual outpatient visits is one of the highest in the world, amounting to about 14 visits per person in the population in 2000. Compared with studies conducted in other countries, subjects in Taiwan have to make a choice between doctors more frequently yet more freely.

Using the unique healthcare system in Taiwan, a large scale survey was performed to determine whether people sought information for choosing between doctors and their propensity to use the information or to change doctors if information on physician performance was available.

\section{METHODS}

Subjects

A nationwide telephone interview survey was conducted using a computer assisted telephone interview (CATI) system with random digit dialling to select subjects aged 20 years or over. In 2000 approximately 6.7 million (98.0\%) households nationwide had telephones. ${ }^{20}$ The telephone interview was conducted by a professional survey agent during a 2 week period in October 2000. Telephone calls were made in the evenings during the weekdays and all day at weekends. Only one attempt was made to call each number. The person answering the telephone was the interviewee, but if he/she was under 20 then anyone over 20 in the household could be the interviewee.

A total of 21352 telephone calls were made; 5381 (25.2\%) were empty numbers, $8058(37.8 \%)$ had no answer, 1115 $(5.2 \%)$ were fax numbers, $1283(6.0 \%)$ were business lines, $920(4.3 \%)$ calls were to a busy line, $469(2.2 \%)$ were rejected, 


\section{Box 1 Healthcare system in Taiwan}

- Taiwan's population density is very high: at the end of 2000 there were 22.3 million people resident on the island of 36000 square kilometres. The per capita gross domestic product of Taiwan at that time was 14000 US dollars (1 USD $=33$ New Taiwan (NT) dollars). At this time there were 29600 Western doctors, 3700 Chinese doctors, and 8600 dentists working in clinics or hospitals, and a total of 699 hospitals and approximately 69000 beds available for acute care. ${ }^{15}$ Most of the hospitals work in a closed system structure; they hire physicians to practise in the hospital and provide outpatient and inpatient services. Medical specialist training programmes and specialist qualifications were started in 1988 but approximately $30 \%$ of practising physicians have not yet undergone any form of specialist training ${ }^{16} \mathrm{~A}$ detailed description of the system can be found elsewhere. ${ }^{17}$

- In 1995 the Taiwanese government launched the compulsory National Health Insurance (NHI) scheme to cover the healthcare needs of all its citizens. Comprehensive benefits are provided by the scheme, including outpatient visits, inpatient hospital stays, dental services, prescribed medications, rehabilitation, etc. Only a small amount of co-payment is required (NT 50-150 dollars) for every outpatient visit. Approximately $94 \%$ of all healthcare providers were contracted with the $\mathrm{NHI}$ in 2000.18 Because of the absence of a referral system in Taiwan, people are free to choose any $\mathrm{NHI}$ contracted physician in clinics or hospitals. The average number of visits per head of population in 2000 was about 14. However, there is no official provision of performance information to help consumers to select healthcare providers. Consulting with relatives and friends is the most popular way of obtaining information about physicians. The impact of the $\mathrm{NHI}$ on healthcare utilisation in Taiwan has been reported previously. ${ }^{19}$

and $111(0.5 \%)$ could not find an eligible interviewee, leaving $4015(18.8 \%)$ calls in which interviews were completed. The response rate (excluding empty numbers, business lines, and fax numbers from the denominator) was $29.6 \%$.

\section{Questionnaire design}

Three questions were developed and modified in a small scale pilot interview with 30 subjects. The first question concerning the research topic in the questionnaire was "Have you ever compared the quality of care provided by doctors in your residential area?" Answers to the question would reveal their experience in searching for information to assist in decision making.

To assess the potential influence of providing performance data on choices made by consumers we then asked interviewees the following two hypothetical questions: (1) "If the local health authority provides information concerning physicians' training, specialist qualifications, and attitude towards patients etc, would you consult the performance report?" and (2) "If the doctors you usually see perform badly on the report, would you change to other doctors?" Alternative answers to these two questions were: definitely would, probably would, probably not, and definitely not.

The following personal characteristics and related questions were also included in the questionnaire as in previous studies $^{821}$ : age, sex, education, family income, perceived health status, medical care utilisation, and usual sources of care. Medical care utilisation was measured by asking the interviewees to refer to their NHI cards which showed the number of healthcare services (outpatient or inpatient) received between the beginning of the year and the time of the interview. The usual sources of care denoted whether a subject had one or several doctors (including specialists) whom they visited frequently.

\section{Data analysis}

Simple frequency distribution was used to show the characteristics of the subjects and their answers to the three research questions. To make the comparisons concise, the analysis combined the answers "definitely would" and "probably would" into the category "yes" and the answers "probably not" and "definitely not" into the category "no". $\chi^{2}$ tests were used to examine the associations between sociodemographic and related factors and the searching behaviour and propensity of their reactions.

\section{RESULTS}

A total of 4015 adults completed the telephone interview. Subjects with missing values to any of the three research variables-comparison of doctors, consulting the report, and changing doctors-were deleted from the analysis, leaving 3814 subjects (95\%) for inclusion in the study. The personal characteristics of the participants and the main results of the analysis are shown in table 1.

Although the interviews were conducted by random digit dialling, the sample might not be representative of the country. The majority of the subjects interviewed were female $(\mathrm{n}=2128,55.8 \%)$ while the proportion of females in the adult population was only $48.8 \%$ in 2000 . The percentages in the three age categories $(20-39,40-59$, and $\geqslant 60$ years $)$ of the interviewees were $52.2 \%, 37.0 \%$, and $10.8 \%(\mathrm{n}=1992$, $\mathrm{n}=1411$, and $\mathrm{n}=411$, respectively) compared with $48.4 \%$, $34.4 \%$, and $17.2 \%$ in the national population. It is therefore important to bear in mind that the study sample was composed of more women and fewer elderly persons than the national population.

1044 persons $(28 \%)$ had spent no more than 9 years at school, while 1534 (52.0\%) had a household income of NT\$ $30000-80000$. About one quarter of the subjects $(n=973)$ had fair or poor perceived health, while 1852 (53.6\%) had visited a physician on fewer than six occasions in the 9 months before the interview. Approximately 69\% of the subjects $(n=2635)$ had usual sources of care.

\section{Had consumers compared physicians?}

The overall proportion of subjects who had made comparisons between doctors on the basis of their quality of care was $49.6 \%(n=1844)$. Men aged over 60 with fewer years of schooling or lower family incomes were less likely to compare doctors in their residential areas. Subjects who had usual sources of care or had more visits to doctors were more likely to make comparisons between doctors.

\section{Would consumers consult the performance reports if available?}

About $73 \%(n=2796)$ of the subjects interviewed stated that they would consult reports of doctors' training, specialist qualifications, and their attitude towards patients if they were available. Those who were older, less educated, or with lower family incomes were less likely to consult performance reports when available. 


\begin{tabular}{|c|c|c|c|c|}
\hline Variables & $\begin{array}{l}\text { No of subjectst } \\
(\mathrm{n}=3814)\end{array}$ & $\begin{array}{l}\text { Compare doctors } \\
(\%)(n=3717)\end{array}$ & $\begin{array}{l}\text { Consult report } \\
\text { (\%) }(n=3814)\end{array}$ & $\begin{array}{l}\text { Change doctors } \\
(\%)(n=3765)\end{array}$ \\
\hline Total & & 49.6 & 73.3 & 76.7 \\
\hline \multicolumn{5}{|l|}{ Sex } \\
\hline Male & 1686 & $47.2^{\star \star}$ & 73.1 & $78.4^{*}$ \\
\hline Female & 2128 & 51.5 & 73.4 & 75.4 \\
\hline \multicolumn{5}{|l|}{ Age (years) } \\
\hline $20-39$ & 1992 & $49.7^{\star \star \star}$ & $78.4^{\star \star \star}$ & $79.7^{* \star \star}$ \\
\hline $40-59$ & 1411 & 52.3 & 71.9 & 76.9 \\
\hline$\geqslant 60$ & 411 & 40.8 & 52.8 & 62.4 \\
\hline \multicolumn{5}{|l|}{ Education (years) } \\
\hline$\leqslant 6$ & 511 & $39.0^{* \star \star}$ & $56.6^{* \star *}$ & $64.0^{* \star *}$ \\
\hline $7-9$ & 533 & 47.5 & 70.6 & 78.7 \\
\hline $10-12$ & 1365 & 50.5 & 77.1 & 78.5 \\
\hline$\geqslant 13$ & 1389 & 53.3 & 77.0 & 79.3 \\
\hline \multicolumn{5}{|c|}{ Family income (NT\$ monthly) } \\
\hline$\leqslant 30000$ & 481 & $45.5^{\star \star}$ & $64.9^{* \star *}$ & 76.3 \\
\hline 30000-79999 & 1534 & 51.4 & 75.9 & 78.0 \\
\hline $80000-150000$ & 714 & 56.2 & 78.6 & 78.5 \\
\hline$\geqslant 150000$ & 221 & 57.9 & 81.5 & 82.5 \\
\hline \multicolumn{5}{|l|}{ Health status } \\
\hline Excellent & 1203 & 47.5 & 72.2 & $77.9^{* * \star}$ \\
\hline Good & 1638 & 50.3 & 74.7 & 78.7 \\
\hline Fair/poor & 973 & 50.6 & 72.2 & 72.0 \\
\hline \multicolumn{5}{|l|}{ Medical care use $\ddagger$} \\
\hline$\leqslant 6$ visits & 1852 & $46.1^{* \star *}$ & 74.8 & $79.1^{*}$ \\
\hline 6-17 visits & 1214 & 53.8 & 74.1 & 78.2 \\
\hline$\geqslant 18$ visits & 390 & 60.9 & 70.5 & 71.9 \\
\hline \multicolumn{5}{|c|}{ Usual sources of care } \\
\hline Yes & 2635 & $54.2^{\star \star \star}$ & 73.6 & $75.2^{\star \star \star}$ \\
\hline No & 1179 & 39.0 & 72.6 & 80.2 \\
\hline
\end{tabular}

\section{Would consumers change doctors on the basis of the reports?}

We proposed a scenario to assess the potential impact of providing physician specific performance information to patients. A total of 2888 respondents $(76.7 \%)$ said that they would change to another doctor if the doctors they usually consulted performed badly according to the reference data. Men who were younger than 60 and with more years of schooling were more likely to change doctors, while subjects with poorer perceived health who visited doctors more often and who had usual sources of care were less likely to change to other doctors.

\section{DISCUSSION}

The findings of our study indicate that providing physician performance information has a significant potential impact on consumers' choice of healthcare providers. A number of previous studies ${ }^{2-6}$ have shown that publicising performance information on health plans or hospitals had only a limited effect on consumer choice. We believe that the key reasons for our positive findings are (1) the physician specific information was easy to understand and (2) the people had the freedom to make such choices. The use of hypothetical scenarios in the questionnaire may be another reason for the positive findings. The hypothetical questions used in the study revealed the most optimistic situation about consumers' use of and reaction to the performance reports, which may not be as ideal in reality.

The study included a large number of subjects, but they were significantly younger with a higher proportion of women than in the national population. In the study we combined the technical and interpersonal performance of physicians into one category-namely, the specialist training of the physician and his/her attitude to patients. We are therefore unable to distinguish between the relative importance of these two factors to the consumer..$^{22}$
Currently in Taiwan there is no official channel through which the public can receive any physician specific performance information. Word of mouth provided by relatives and friends is the main source of information about physician performance. ${ }^{11}{ }^{23}$ Searching for physician related information is somewhat costly (that is, time consuming). This explains why $73 \%$ of interviewees reported that they would consult such a report while only about half of the subjects surveyed had ever compared the quality of care provided by doctors. We also found that younger subjects and those with a higher level of education were more likely to consult the performance reports. These factors should be taken into account when considering the logistics of dissemination of performance data in the future.

The potential impact of providing physician specific information to consumers is clearly apparent. Approximately $77 \%$ of all the respondents stated that they might change to another doctor if their usual doctor performed badly according to the reference data. This findings supports the suggestion by Hibbard and colleagues ${ }^{24}$ that providing risk messages (which emphasise protecting oneself from possible risk) may have a positive impact on how consumers comprehend and value the performance information. As Taiwan's NHI scheme allows beneficiaries to choose any contracted physicians for each visit, and travel costs and co-payment requirements are relatively low, it is very easy for subjects in our study to change doctors.

Since the absence of consumer pressure may be viewed as a potential barrier to a market led initiative to improve quality in care and consumers are not familiar with comparative healthcare quality indicators, ${ }^{79}$ new easy to understand indicators need to be developed to increase their usefulness. With the well developed methods of patient survey now available, ${ }^{25}$ consumer assessed physician performance may help consumers to make choices and thus accelerate improvements in the quality of health care. Improvements 


\section{Key messages}

- The public release of performance information of healthcare providers has had only a limited impact on consumer choice.

- The possible reasons for this are lack of familiarity of consumers with comparative healthcare quality information and a limited number of providers from which they can choose.

- A nationwide telephone survey was performed in Taiwan, where consumers are free to choose a healthcare provider for each consultation.

- Half the subjects had compared the quality of care provided by doctors in their area, $73 \%$ said they would consult a performance report if it was available, and $77 \%$ said they would change doctors if their doctor performed badly in the report.

- Providing physician performance information to consumers with the freedom to choose doctors may have a significant impact on physician selection and hence quality improvement.

in the methods of gathering accurate and understandable information and the modes for disseminating performance reports are important objectives for future studies.

\section{ACKNOWLEDGEMENTS}

The authors appreciate the comments and suggestions provided by the editor and reviewers and would like to thank Miss Kuan-Yi Wang and Shu-Hui Chen for their assistance.

\section{Authors' affiliations}

S-H Cheng, H-Y Song, Institute of Health Policy and Management and Center for Health Policy Research, College of Public Health, National Taiwan University, Taipei, Taiwan

The study was supported in part by grants from the National Science Council (NSC90-2415-H-002-025) and the National Health Research Institutes (NHRI-EX91-8801PP) in Taiwan.

\section{REFERENCES}

1 Davies HT, Marshall MN. Public disclosure of performance data: does the public get what the public wants? Lancet 1999;353:1639-40.
2 Marshall MN, Shekelle PG, Leatherman S, et al. The public release of performance data: what do we expect to gain? A review of the evidence. JAMA 2000;283:1866-74.

3 Mukamel DB, Mushlin Al. The impact of quality report cards on choice of physicians, hospitals, and HMOs: a midcourse evaluation. Jt Comm J Qual Improv 2001;27:20-27.

4 Schauffler HH, Mordavsky JK. Consumer reports in health care: do they make a difference? Ann Rev Public Health $2001 ; 22: 69-89$.

5 Beaulieu ND. Quality information and consumer health plan choice. J Health Econ 2002;21:43-63.

6 Fowles JB, Kind EA, Braun BL, et al. Consumer responses to health plan report cards in two markets. Med Care 2000;38:469-81.

7 Robinson S, Brodie M. Understanding the quality challenge for health consumers: the Kaiser/AHCPR survey. It Comm J Qual Improv 1997;23:239-44.

8 Schneider EC, Epstein AM. Use of public performance reports: a survey of patients undergoing cardiac surgery. JAMA 1998;279:1638-42.

9 Cheng SH, Ho YC, Chung KP. Hospital quality information for patients in Taiwan: can they understand it? Int J Qual Health Care 2002;14:155-60.

10 Eddy DM. Performance measurement: problems and solutions. Health Affairs 1998;17:7-25.

11 Hibbard JH, Jewett JJ, Legnini MW, et al. Choosing a health plan: do large employers use the data? Health Affairs 1997;16:172-80.

12 Spranca $M$, Kanouse DE, Elliott $M$, et al. Do consumer reports of health plan quality affect health plan selection? Health Serv Res 2000;35:933-47.

13 Guadagnoli E, Epstein AM, Zaslavsky A, et al. Providing consumers with information about the quality of health plan: the consumers' assessment of health plan demonstration in Washington State. It Comm J Qual Improv 2000;26:410-20.

14 Goldstein E, Fyuck J. Reporting of CAHPS quality information to Medicare beneficiaries. Health Serv Res 2001;36:477-88.

15 Bureau of National Health Insurance, Taiwan, Republic of China. www.nhi.gov.tw/00english/e_index.htm (accessed 4 July 2002).

16 Department of Health. Health and vital statistics. I: General health statistic, 2000: Republic of China. Taipei, Taiwan: Department of Health, the Executive Yuan, 2001;125:110-4.

17 Chang MS. The status and planning of specialty manpower. Paper presented at the Conference on Health Manpower Planning and Forecasting in Taiwan.Taipei, Taiwan, November 2000:28-9.

18 Peabody JW, Yu JC-I, Wang Y-R, et al. Health system reform in the Republic of China: formulating policy in a market-based health system. JAMA 1995;273:777-81

19 Cheng SH, Chiang TL. The effect of universal health insurance on health care utilization in Taiwan: result from a natural experiment. JAMA 1997:278:89-93.

20 Directorate-General of Budget, Accounting and Statistics. Social indicators in Taiwan area of the Republic of China, 2000. Taipei, Taiwan: DirectorateGeneral of Budget, Account and Statistics, The Executive Yuan, 2001:46.

21 Anell A, Rosen P, Hjortsberg C. Choice and participation in health services: a survey of preference among Swedish residents. Health Policy 1997; 40: 157-68

22 Donabedian A. The quality of care: how can it be assessed? JAMA 1988;260:1743-8.

23 Hsieh HS, Cheng SH, Lew-Ting CY. Demand for provider selection information of inpatients: findings from a preliminary study. Chin J Public Health (Taipei) 2000;19:437-45.

24 Hibbard JH, Harris-Kojetin L, Mullin P, et al. Increasing the impact of health plan report cards by addressing consumers' concerns. Health Affairs 2000; 19:138-43.

25 Cleary PD. The increasing importance of patient survey: now that sound methods exist, patient surveys can facilitate improvement. BMJ 1999;319:720-1. 